\title{
Isolated Gallbladder Metastasis from Renal Cell Carcinoma: A Case Report and Review of the Literature
}

\author{
Mitsimponas $\mathbf{N}^{1 *}$, Crespo $\mathrm{F}^{1}$, Zarras $\mathrm{K}^{2}$, Diederich \\ $\mathrm{S}^{3}$, Klosterhalfen $\mathrm{B}^{\mathbf{4}}$ and Giagounidis $\mathrm{A}^{\mathbf{1}}$ \\ ${ }^{1}$ Department of Oncology, Hematology and Palliative \\ Care, Marien Hospital Dusseldorf, Germany \\ ${ }^{2}$ Department of Surgery, Marien Hospital Düsseldorf, \\ Germany \\ ${ }^{3}$ Department of Radiology, Marien Hospital Düsseldorf, \\ Germany \\ ${ }^{4}$ Department of Pathology, Marien Hospital Düsseldorf, \\ Germany \\ *Correspondling author: Nikolaos Mitsimponas, \\ Department of Oncology, Hematology and Palliative Care, \\ Marien Hospital Dusseldorf, Rochusstrasse 2, D-40479, \\ Germany
}

Received: March 14, 2017; Accepted: April 19, 2017; Published: May 05, 2017

\begin{abstract}
Isolated gallbladder metastasis from renal cell carcinoma is a very rare clinical entity with a significant male predominance. Until now, only 22 cases have been reported in the medical literature. Most cases occurred after very prolonged disease-free intervals. We report a case of metachronous isolated gallbladder metastasis of $15 \mathrm{~mm}$ size in a $72 \mathrm{yr}$ old gentleman, 12 years after subtotal nephrectomy of the upper pole of the right kidney for clear cell renal cell carcinoma. At the time of diagnosis, the patient suffered from concurrent aggressive B-cell non-Hodgkin's lymphoma which was treated aggressively, including autologous bone marrow transplantation. Gallbladder resection was performed after treatment of the hematological malignancy. Small polypoid structures in the gallbladder of patients with antecedents of renal cell carcinoma should prompt surgical resection even if the size in ultrasound does not reach internationally accepted intervention thresholds for benign gall bladder polyps.
\end{abstract}

Keywords: Isolated gallbladder metastasis; Renal cell carcinoma; Surgical resection; B-cell-non-hodgkin-lymphoma

\section{Abbreviations}

RCC: Renal Cell Carcinoma; CNS: Central Nervous System; CT: Computed Tomography; NHL: Non-Hodgkin Lymphoma; FDGPET: Fluorodeoxyglucose-Positron Emission Tomography

\section{Introduction}

Renal cell carcinoma (RCC) is the most common malignant disease of the kidney, representing more than $90 \%$ of all cancers affecting this organ, followed by urothelial carcinoma of the renal pelvis and rare cases of kidney lymphoma or sarcoma. Approximately $20 \%-30 \%$ of patients with RCC have metastatic disease at presentation. Close to $50 \%$ of patients with advanced disease will develop metastatic disease within 5 years of diagnosis. The most common histological type is clear cell tumor (70-75\%). Papillary RCC and chromophobe RCC account for $15 \%-20 \%$ [1]. The most frequent sites of metastasis are lung $(55 \%)$, regional lymph nodes (34\%), liver (33\%), bones (32\%), adrenal (19\%), contralateral kidney (11\%) and CNS (6\%) [2]. More than 230 cases of metastasis to the pancreas have been described. In contrast, the gallbladder is very rarely a target for metastasis of RCC, but was occasionally involved in malignant melanoma [1,3,4], stomach, pancreas, ovary, colon, biliary duct and breast carcinomas [1]. We report the case of a male patient who developed isolated renal cell carcinoma metastasis to the gallbladder which was incidentally found while he was being treated for aggressive non-Hodgkin's lymphoma.

\section{Case Presentation}

This $72 \mathrm{yr}$ old gentleman was diagnosed in 2002 with renal cell carcinoma of the upper pole of the right kidney and underwent subtotal nephrectomy.12 years later, in August 2014, he presented with rapid onset ascites and underwent diagnostic laparoscopy which revealed aggressive B-cell non-Hodgkin's lymphoma. The initial CT staging showed a partly calcified, ovoid and polypoid mass measuring $15 \mathrm{~mm}$ within the gallbladder, thought to be a gallbladder calculus. The abdominal ultrasound examination also confirmed a $15 \mathrm{~mm}$ structure within the gall bladder, in keeping with a benign gall bladder polyp. The patient was treated with 6 courses of intensive polychemotherapy including methotrexate, anthracyclines, cyclophosphamide, vincristine, etoposide and cytarabin as described elsewhere [5]. In January 2015, the patient underwent autologous stem cell transplantation. During follow-up, the $15 \mathrm{~mm}$ polypoid mass within the gallbladder was reevaluated and operative removal scheduled to prevent malignant evolution. Histopathology revealed renal clear cell carcinoma of $23 \mathrm{~mm}$ diameter in the mucosal wall. Immunohistochemistry showed positivity for vimentin and pancytokeratin, and negativity for CK7, CEA, chromogranin, synaptophysin and CD68.

Morphological correlation with the initial tumor of 2002 corroborated the finding of late onset metastasis of RCC. The patient later relapsed of aggressive non-Hodgkin's lymphoma in 2015 and succumbed to this disease.

\section{Discussion}

Metachronous, isolated metastasis of renal cell carcinoma to the gallbladder is an extremely rare finding and only 22 cases have been reported in the literature so far [6]. The median disease free interval between primary operation for RCC and metachronous gallbladder metastasis (isolated or in the context of multiple other sites of metastasis) has been reported to be 3.1 to 7.4 years with the longest intervals spanning up to 27 years [6-8]. Table 1 summarizes cases of isolated metachronous metastasis to the gallbladder. These cases occur after long disease-free intervals (median time to diagnosis 6 years), with a strong male predominance $(87 \%)$. The majority of the cases were diagnosed in asymptomatic patients $(63 \%)$. Our case 
Table 1: Solitary metachronous metastasis of renal cell carcinoma to the gallbladder.

\begin{tabular}{|c|c|c|c|c|c|}
\hline Author & Age & Sex & DFI & Symptoms & Size $(\mathrm{mm})$ \\
\hline Botting, et al. 1963 [26] & 66 & M & 1.5 & NA & $42 \times 20$ \\
\hline Golbey, et al.1991 [27] & 84 & M & 13 & None & 35 \\
\hline Nagler, et al. 1994 [28] & 82 & M & 5 & None & $30 \times 30$ \\
\hline Lombardo, et al. 1996 [2] & 77 & M & 5 & None & $30 \times 30$ \\
\hline Sparwasser, et al. 1997 [3] & 46 & M & 3.7 & Abdominal pain & $27 \times 21$ \\
\hline \multirow[t]{2}{*}{ Aoki, et al. 2002 [21] } & 63 & M & 27 & None & $75 \times 30$ \\
\hline & 80 & M & 8 & None & $45 \times 25$ \\
\hline Miyagi, et al. 2003 [29] & 53 & M & 10.5 & None & $25 \times 15$ \\
\hline Park, et al. 2003 [30] & 48 & M & 2 & None & NA \\
\hline Itoh, et al. 2004 [20] & 53 & M & 11 & None & $25 \times 25$ \\
\hline Ishizawa, et al. 2006 [23] & 73 & M & 5 & None & $30 \times 20$ \\
\hline Pandey, et al. 2006 [31] & 46 & M & 1 & Abdominal pain & NA \\
\hline Patel, et al. 2009 [32] & 64 & $\mathrm{~F}$ & 6 & Acute biliary syndrome, upper back pain & 30 \\
\hline Biolchini, et al. 2009 [33] & 77 & $\mathrm{~F}$ & 13 & None & $115 \times 5$ \\
\hline Fang, et al. 2010 [19] & 54 & M & 7 & None & $15 \times 10$ \\
\hline Mazzei, et al. 2010 [34] & 73 & M & 5 & Acute biliary syndrome & NA \\
\hline Collin, et al. 2012 [35] & 68 & M & NA & None & NA \\
\hline Vaziri, et al. 2012 [36] & 57 & M & NA & Abdominal pain & 22 \\
\hline McWhirter, et al. 2013 [37] & 74 & M & 14 & Acute biliary symptom & $22 \times 23$ \\
\hline Jain, et al. 2013 [38] & 49 & $\mathrm{~F}$ & 6 & Right upper quadrant abdominal pain & $20 \times 18$ \\
\hline Win, et al. 2014 [13] & 62 & M & 21 & Acute biliary syndrome & 40 \\
\hline Ueda, et al. 2015 [39] & 43 & M & 1 & None & 26 \\
\hline
\end{tabular}

was an incidental finding during staging for aggressive NHL and asymptomatic regarding the gallbladder. Abdominal ultrasound is a convenient and reliable tool in the diagnosis of gallbladder tumors. Metastases can appear as hyperechoic masses bigger than $1 \mathrm{~cm}$ in diameter, close to the gallbladder wall without posterior acoustic shadowing [9-12]. A CT sign that can help in the differentiation between primary gallbladder tumors and metastases is the invasion of the mucosal layer. When the mucosal layer is not infiltrated, a primary gallbladder tumor can be excluded [6]. Moreover, the majority of cases of metastatic renal cell carcinoma to the gallbladder reported in the literature presented themselves as polypoid masses [6]. Therefore, in patients with a history of renal cell carcinoma and a polypoid gallbladder mass in computed tomography, a metastasis of the RCC should be included in the differential diagnosis. The role of PET-CT in the diagnostic of the gallbladder metastases of RCC remains questionable. While Robeldo, et al. denied any benefit from using PET-CT to detect gallbladder metastasis [6], Win et al. claimed that FDG-PET is a useful and good diagnostic tool in mRCC because it can detect cancers before anatomic changes are perceptible [13]. Removal of gall bladder polyps in otherwise healthy subjects is usually advocated for sizes exceeding $10 \mathrm{~mm}[14,15]$. For polyps between 6 and $10 \mathrm{~mm}$ regular follow-up with ultrasound is usually recommended [15-17]. In patients with a history of RCC, a more active approach seems prudent. As a matter of fact, the median tumor size at diagnosis of gall bladder metastasis of RCC in the literature was $3 \mathrm{~cm}$ (range, 1.1-7.5). The case reported here had a very long interval from diagnosis of RCC metastasis to operation (12 years), and the removed specimen measured $2.3 \mathrm{~cm}$. RCC metastases to the gallbladder have a low incidence of concomitant gallstone disease $[8,18,19]$. There is certain variability in the histological findings of gallbladder metastasis from RCC. The majorities of metastases has a polypoid or pedunculated morphology and often begin as a submucosal nodule that eventually becomes pedunculated $[8,18,20]$. In this case metastastic gallbladder carcinoma may resemble primary carcinoma of the gallbladder. Metastatsis may be limited to the muscle layer and perimuscular connective tissue and doesn't necessarily involve the mucosa $[6,8,18,21]$. In immunohistochemistry, primary carcinoma of the gallbladder is positive for CK7 and CEA, while metastatic RCC is negative for these antigens [22]. In contrast RCC metastasis would be positive for vimentin, pancytoceratin and CD10 but negative for CEA, CK7, chromogranin, synaptophysin and CD68, which indeed happened with our patient $[1,19,23]$. Isolated metastasis of RCC is preferentially treated with surgical resection after multidisciplinary review, especially for solitary or easily accessible pulmonary metastases, solitary resectable intra-abdominal metastases, especially if there is a long disease-free interval after nephrectomy, or a partial response of metastases to immunotherapy or targeted therapy [24]. In fact, in all patients with metastatic renal cell cancer, those deriving the largest benefit from surgery were patients with a recurrence-free interval of above 12 months $v s$. less 
than 12 months ( $55 \%$ vs. $9 \% 5$ year survival, $\mathrm{p}<0.0001$ ), solitary versus multiple sites of metastasis ( $54 \%$ vs. $29 \% 5$ year survival, $\mathrm{p}<0.001$ ), and age $<60$ years ( $49 \%$ versus $35 \% 5$ year survival, $p=0.05$ ) [25]. Overall survival rates of patients with solitary metachronous gallbladder metastasis exceeded $90 \%$ in two series $[7,19]$. Renal cell carcinoma is considered a chemotherapy resistant entity and, in our patient, 6 courses of intensive polychemotherapy followed by autologous stem cell transplantation failed to significantly reduce the size of the tumor. On the other hand, the profound immune suppression inflicted by aggressive chemotherapy did not lead to any relevant growth of the tumor, which remained almost stable in size as measured by noninvasive radiological imaging throughout the therapy for NHL.

\section{References}

1. Ghaouti M, Znati k, Jahid A, Zouaidia F, Bernoussi Z, El Fakir Y, et al. A gallbladder tumor revealing metastatic clear cell carcinoma: report of case and review of literature. Diagnostic Pathology. 2013; 8: 4-9.

2. Lombardo FP, Hertford DE, Shanahan EM, Kazam E. Color Doppler ultrasonographic evaluation of renal cell carcinoma metastasis to the gallbladder. J Ultrasound Med. 1996; 15: 725-728.

3. Sparwasser C, Krupienski M, Radomsky J, Pust RA. Gallbladder metastasis of renal cell carcinoma. A case report and review of the literature. Urol Int. 1997; 58: 257-258.

4. Limani K, Matos C, Hut F, Gelin M, Closset J. Metastatic carcinoma of the gallbladder after a renal cell carcinoma. Acta Chir Belg. 2003; 103: 233-234.

5. Schwarzbich MA, Schöning T, Cremer M, Lisenko K, Ho AD, Witzens-Harig M Efficacy and toxicity of a rituximab and methotrexate based regimen (GMALL B-ALL/NHL 2002 protocol) in high risk diffuse large cell B-cell lymphoma patients as a first line treatment. Leuk Lymphoma. 2016; 57: 1723-1726.

6. Castro Ruiz C, ZizzoM, Ugoletti L, Giunta A, Pedrazzoli C. Gallbladder's clear cell renal cell carcinoma metastasis: a systematic review of the literature. Cancer Cell \& Microenvironment. 2016; 3: e1240.

7. Chung PH, Srinivasan R, Linehan WM, Pinto PA, Bratslavsky G. Renal cell carcinoma with metastases to the gallbladder: four cases from the National Cancer Institute (NCI) and review of the literature. Urol Oncol. 2012; 30: 476481.

8. Costa Neves M, Neofytou K, Giakoustidis A, Hazell S, Wotherspoon A. Two cases of gallbladder metastasis from renal cell carcinoma and review of literature. World J Surg Oncol. 2016; 14: 87.

9. Robledo AB, Millet SB, Orbis Castellanos JF, Montalvá Orón EM, Salom Fuster JV, DE Juan Burgueño M. Metastasis of the gallbladder in clear cell renal carcinoma. Oncol Lett. 2012; 3: 1136-1138.

10. Reiser M, Oehmen F, Walter H, Büsing M. Contrast enhanced ultrasound of a gallbladder lesion in a patient with a history of renal cell and rectal cancer. Case Rep Gastrointest Med. 2013.

11. Sountoulides P, Metaxa L, Cindolo L. Atypical presentations and rare metastatic sites of renal cell carcinoma: a review of case reports. J Med Case Rep. 2011; 5: 429.

12. Barretta ML, Catalano O, Setola SV, Granata V, Marone U, D’Errico Gallipol A. Gallbladder metastasis: spectrum of imaging findings. Abdom Imaging. 2011; 36: 729-734.

13. Win AZ. Renal cell carcinoma metastasis to the gallbladder detected by FDGPET/CT. J Clin Med Res. 2014; 6: 482-486.

14. Kubota K, Bandai Y, Noie T, Ishizaki Y, Teruya M, Makuuchi M. How should polypoid lesions of the gallbladder be treated in the era of laparoscopic cholecystectomy? Surgery. 1995; 117: 481-487.

15. Anderson MA, Appalaneni V, Ben-Menachem T, Decker GA, Early DS, Evans JA, et al. The role of endoscopy in the evaluation and treatment of patients with biliary neoplasia. Gastrointest Endosc. 2013; 77: 167-174.

16. Koga A, Watanabe K, Fukuyama T, Takiguchi S, Nakayama F. Diagnosis and operative indications for polypoid lesions of the gallbladder. Arch Surg. 1988; 123: 26-29.

17. Koga A, Yamauchi S, Nakayama F. Primary carcinoma of the gallbladder. Am Surg. 1985; 51: 529-533.

18. Piehler JM, Crichlow RW. Primary carcinoma of the gallbladder. Arch Surg. 1977; 112: 26-30.

19. Fang X, Gupta N, Shen SS, Tamboli P, Charnsangavej C, Rashid A, et al. Intraluminal polypoid metastasis of renal cell carcinoma in gallbladder mimicking gallbladder polyp. Arch Pathol Lab Med. 2010; 134: 1003-1009.

20. Itoh H, Nishijima K, Kurosaka Y, Takegawa S, Kiriyama M, Dohba S, et al. Asymptomatic metachronous solitary metastasis to the gallbladder from renal cell carcinoma: report of a case. Chir Gastroenterol. 2004; 20: 153-156.

21. Aoki T, Inoue K, Tsuchida A, Aoki T, Kasuya K, Kitamura K, et al. Gallbladder metastasis of renal cell carcinoma: report of two cases. Surg Today. 2002; 32: 89-92.

22. Shoji S, Mukai M, Yazawa N, Sekido Y, Nagata Y, Uchida T, et al. Metastasis to gallbladder and adrenal gland of renal cell carcinoma. Oncol Lett. 2010; 1: 507-509.

23. Ishizawa T, Okuda J, Kawanishi T, Kitagawa T, Yakumaru K, Sekikawa T. Metastatic renal cell carcinoma of the gallbladder. Asian J Surg. 2006; 29: 145-148.

24. Escudier B, Porta C, Schmidinger M, Rioux-Leclercq N, Bex A, Khoo V, et al. on behalf of the ESMO Guidelines Committee. Renal cell carcinoma: ESMO Clinical Practice Guidelines for diagnosis, treatment and follow-up. Ann Oncol. 2016; 27: v58-v68.

25. Kavolius JP, Mastorakos DP, Pavlovich C, Russo P, Burt ME, Brady MS. Resection of metastatic renal cell carcinoma. J Clin Oncol. 1998; 16: 22612266.

26. Botting Aj, Harrison Eg Jr, Black Bm. Metastatic hypernephroma masquerading as a polypoid tumor of the gallbladder and review of metastatic tumors of the gallbladder. Proc Staff Meet Mayo Clin. 1963; 38: 225-232.

27. Golbey S, Gerard PS, Frank RG. Metastatic hypernephroma masquerading as acute cholecystitis. Clin Imaging. 1991; 15: 293-295.

28. Nagler J, McSherry CK, Miskovitz P. Asymptomatic metachronous metastatic renal cell adenocarcinoma to the gallbladder. Report of a case and guidelines for evaluation of intraluminal polypoid gallbladder masses. Dig Dis Sci. 1994; 39: 2476-2479.

29. Miyagi T, Kitagawa $Y$, Katsumi T, Takegawa S, Kobayashi A, Watanabe $\mathrm{K}$, et al. A case of metastatic gallbladder tumor from unilateral renal cell adenocarcinoma. Japanese J Clin Urol. 2003; 57: 257-259.

30. Park JS, Chae YS, Hong SJ, Shin DH, Choi JS, Kim BR. Metastatic renal cell carcinoma of the gallbladder. Yonsei Med J. 2003; 44: 355-358.

31. Pandey D, Kane SV, Shukla PJ, Shrikhande SV, Tongaonkar HB. Isolated gall bladder metastasis from renal cell carcinoma. Indian J Gastroenterol. 2006; 25: 161-162.

32. Patel S, Zebian B, Gurjar S, Pavithran N, Singh K, Liston T, et al. An unusual gall-bladder polyp--site of metastatic renal cell carcinoma: a case report. Cases J. 2009; 2: 172.

33. Biolchini F, Giunta A, Sandonà F, Ronzoni R, Ugoletti L, Tumiati B. Metastasi singola colecistica di neoplasia renale a cellule chiare. G Chir. 2009; 30: 184185.

34. Mazzei S, Tagliabue F, Acquaro P, Chiarelli M, Origi M, Confalonieri G, et al. Gallbladder Metastasis of renal cell carcinoma: A case report. Eur Surg Res. 2010; 45: 185.

35. Collin Y, Sabbagh R. An unusual case of pancreatitis revealing a metachronous renal cell carcinoma metastasis to the gallbladder. Can J Urol. 2012; 19: 6392-6394.

36. Vaziri R, Rodriguez-Justo M, Winstanley A, Feakins RM. An Unusual case of metastatic renal cell carcinoma presenting as a gallbladder polyp. Pathological Society. Winter Meeting. 2012; 226: S25. 
37. McWhirter D, den Dulk M, Terlizzo M, Malik HZ, Fenwick SW, Poston GJ. Renal cell carcinoma metastases to gallbladder. Ann R Coll Surg Engl. 2013; 95: e136-8.

38. Jain D, Chopra P. Metastatic renal cell carcinoma of gall bladder. Saudi J Kidney Dis Transpl. 2013; 24: 100-104.
39. Ueda I, Aoki T, Oki H, Takahashi H, Hayashida $\mathrm{Y}$, Minagawa $\mathrm{N}$, et al. Gallbladder metastasis from renal cell carcinoma: a case report with review of the literature. Magn Reson Med Sci. 2015; 14: 133-138.
Ann Hematol Oncol - Volume 4 Issue 5 - 2017

ISSN : 2375-7965 | www.austinpublishinggroup.com

Mitsimponas et al. (C) All rights are reserved
Citation: Mitsimponas N, Crespo F, Zarras K, Diederich S, Klosterhalfen B and Giagounidis A. Isolated Gallbladder Metastasis from Renal Cell Carcinoma: A Case Report and Review of the Literature. Ann Hematol Oncol. 2017; 4(5): 1149 